\title{
КОМПЛЕКСНАЯ МОДЕРНИЗАЦИЯ ПРОМЫШЛЕННОГО ПРЕДПРИЯТИЯ В УСЛОВИЯХ РАЗВИТИЯ ЦИФРОВЫХ ТЕХНОЛОГИЙ
}

\author{
(c) 2018 Вейг Наталья Васильевна \\ кандидат экономических наук, доцент \\ докторант кафедры экономики и управления предприятиями и производственными комплексами \\ Санкт-Петербургский государственный экономический университет \\ 191023, Санкт-Петербург, ул. Садовая, д. 21 \\ E-mail:veyg_natalia@mail.ru
}

В статье рассматриваются вопросы модернизации производственного аппарата машиностроительных и других высокотехнологичных предприятий как основы развития российской экономики. Особое внимание в статье уделяется проблеме модернизации системы информационного обеспечения промышленного предприятия, показаны положительные и негативные моменты смены программного обеспечения.

Ключевые слова: модернизация, модернизация промышленного предприятия, информационное обеспечение, программное обеспечение деятельности предприятия.

Современное состояние российской экономики по имеющимся прогнозам оставляет желать лучшего. Так, Международный валютный фонд понизил прогноз роста экономики России в 2019 и 2020 годах до 1,6\% и 1,7\% соответственно, при этом показатели роста снизились по сравнению с предсказанными тем же МВФ в октябре 2018 года на 0,2 и 0,1 процентного пункта соответственно [4]. Конечно же, существует ряд объективных причин замедления темпов роста. Это и санкционная политика западных стран, и ряд ресурсных ограничений, возникших не в последние годы, но наиболее ярко проявившие себя именно в настоящий период. Тем не менее, если более глубоко подходить к сложившейся ситуации, то следует прийти к выводу, что в основе лежит неразвитость базы развития экономики любой страны - машиностроения.

Проблема повышения эффективности российской экономики в современных условиях неразрывно связана с решением ряда вопросов, касающихся практически всех сторон ее развития и, в первую очередь, развития машиностроительного комплекса. Действительно, в настоящее время именно машиностроение может и должно стать основой трансформации российской экономики на базе высоких промышленных технологий, внедрение которых обеспеченно информационной инфраструктурой, в том числе цифровыми технологиями. Можно ли в полной степени охарактеризовать предполагаемые и уже происходящие изменения перехода к высокотехнологичным производствам как мо- дернизацию промышленности, предприятий?

Генезис термина «модернизация промышленности, предприятия» достаточно интересен. Сам термин модернизация первоначально сформировался на мега- и макроуровне как процесс трансформации сложившихся обществ, находящихся на более низком уровне развития по отношению к современному цивилизованному обществу [7]. Он же формулировался как процесс «перехода к индустриальному обществу» (нужно упомянуть, что последний часто отождествляют с процессом индустриализации, хотя, на наш взгляд, это в корне неверно). Лозунг модернизации сопровождал практически все экономическое развитие постсоветской России и достиг своего апогея в статье Д.А. Медведева «Россия, вперед!» (2010 г.), в которой излагалась программа перемен в России во всех сферах экономической и социальной жизни, в результате чего Россия должна была выйти на уровень развитых стран мира одновременно с развитием демократии.

Если мы вернемся к вопросу модернизации промышленного предприятия, то, как правило, под модернизацией его подразумевалось трансформация производственного аппарата, в первую очередь, технологического оборудования. При этом каждый автор, рассматривающий проблему модернизации предприятий, практически дает свои, незначительно отличающиеся, определения. Так, например, Ермакова Ж.А. дает определения модернизации для производственных систем, основных фондов, 
промышленного предприятия, а в свете этого определяет модернизацию, как приведение в соответствие текущих или будущих ожиданий, выявленных в результате взаимодействия объектных и субъектных факторов, не противоречащих институциональной среде и направленное на снижение трансформационных издержек по обеспечению временной монополии текущего и будущих периодов[2]. Свое определение дают и Ковальчук Ю.А.[3], Щепетов А.В.[6] и другие. Не вдаваясь в подробности определения понятия «модернизация предприятия», воспользуемся наиболее приемлемым для целей исследования следующим, дополненным нами определением: модернизация промышленного предприятия - мобилизация потенциала промышленного предприятия и приведение его к более высокой стадии развития на основе повышения эффективности использования как уже имеющихся ресурсов, так и вновь вводимых в процесс развития с учетом ускорения трансформации социально-экономической и технологической среды. На наш взгляд, следует сконцентрироваться именно на ресурсах, которыми обладает предприятия и их развития под влиянием тех или иных факторов для выхода на новый уровень технологического и экономического развития.

«Современный экономический словарь» к экономическим ресурсам относит «природные (сырьевые геофизические), трудовые (человеческий капитал), капитальные (физический капитал), оборотные средства (материалы), информационные ресурсы, финансовые (денежный капитал», хотя тут же признает подобную классификацию строго неоднозначной [5]. И, тем не менее, на наш взгляд основные и наиболее значимые ресурсы предприятия здесь обозначены.

Современное промышленное предприятие представляет собой сложную систему, особенно, учитывая появление новых форм взаимодействия предприятий: сетевых, виртуальных и др. Развитие предприятий в современных условиях однозначно требует прорыва и в технологическом плане. При этом и то и другое невозможно без использования информационных технологий, сложной системы информационного обеспечения. Если с изменением уровня технологий на предприятии, модернизацией непосредственно производственного аппарата, опережающей подготовкой персонала для перспективных фабрик будущего более или менее понятно, то проблема информационного обеспечения на основе внедрения цифровых технологий является для предприятия одной из наиболее сложных и капиталоемких.

Проблема заключается в том, что необходимо поддержать новые технологические системы основного производства соответствующим информационным обеспечением с использованием более современных цифровых технологий, адаптированных к новой технологической системе. Здесь можно рассмотреть несколько аспектов. Часть данной проблемы заключается в том, что уже действующая на предприятии информационная система (которая может быть основана на устаревших по отношению ко времени модернизации технологиях) необходима в текущей деятельности предприятия. Вторая сторона проблемы заключается в том, сама система, вне зависимости от срока ее разработки и срока функционирования на данном предприятии, уже не удовлетворяет потребностям предприятия как с точки зрения соответствия современным технологиям, так и из-за невозможности (или высокой стоимости) ее поддержки и развития. Сюда же необходимо отнести и невозможность объединения действующей системы с новыми, по тем или иным причинам, к которым можно отнести существующую архитектуру, дизайн или основную технологию. В данном случае все затраты, которые связаны с процессом улучшения или поддержки могут быть признаны явными затраты предприятия.

Если говорить о так называемых скрытых затратах предприятия в этой сфере, то, в первую очередь, это относится к тому, что данные системы представляют собой определенную целостность, где невозможно просто изменить или заменить один системный модуль. Сравнительно незначительные (с внешней точки зрения) обновления могло бы привести к необходимости вносить изменения в остальные модули, что потребует, как дополнительных денежных, так и так и определенных временных затрат.

Несколько слов об инфраструктуре системы информационного обеспечения деятельности предприятия. Инфраструктура становится более дорогой, чтобы поддержать стареющую систему информационного обеспечения. Необходима соответствующая техническая окружающая среда, включая аппаратные средства. Таким образом, расходы обслуживания инфраструктуры растут по сравнению с обслуживанием совре- 


\section{менных систем}

Сюда же можно отнести и проблему кадров (персонала). Обслуживание устаревших информационных технологий требует определенного набора навыков и экспертизы, и здесь может возникнуть дефицит персонала. Во-первых, специалисты, которые разработали программное обеспечение, могли бы переключиться на другие технологии, становится более трудно найти и сохранить тех, кто может обслуживать устаревшие технологии - этому не учат. Специализированная же подготовка кадров для обслуживания устаревшей системы информационного обеспечения могла бы быть еще большим источником расхода.

Еще один аспект, который необходимо учитывать при модернизации Инфраструктура действующей информационной системы может стать одной из главных угроз кибербезопасности. Действительно, устаревшие системы являются обычно более уязвимыми к кибернападениям, вредоносным программам. Если программный продукт использовался в течение многих лет, у нападавших было достаточно времени, чтобы стать знакомыми с его уязвимостью и найти слабые места. Другая причина этого состоит в том, что устаревшее программное обеспечение больше не может поддерживаться продавцом. Это означает, что безопасность отдельных позиций не обеспечивается. Даже если система изготовлена на заказ, и наличествуют ресурсы для ее поддержки, это означает дополнительные инвестиции в безопасность.

Вкладывая капитал в поддержку установленного программного обеспечения и его обслуживание, предприятие оставляет все меньше возможностей для его обновления. Вместо того, чтобы принять новые технологии и бизнес-модели, предприятие остается со старым программным обеспечением, что означает сокращение возможностей перестройке основного производства. Последнее же предоставляет возможности «отрыва» для конкурентов и потенциального захвата большей доли на рынке

Тем не менее, несмотря на проблемы и определенные риски, связанные с устаревшим программным обеспечением, ряд компаний не инициирует его модернизацию, а приступает к этой процедуре только в экстраординарных случаях, например, полного падения системы.

Естественно, что вообще разговор о модернизации системы информационного обе- спечения может идти только после подготовки соответствующего технико-экономического обоснования. При этом, необходимо учитывать не только чисто экономические моменты, но и социальные, связанные в том числе, с отношением действующего персонала к будущей модернизации.

Также, как и установка новой системы, модернизация системы информационного обеспечения технологической трансформации, является не просто дорогим мероприятием, но и растянутым по времени. Это несомненно влияет на общую стоимость модернизации, включая недополученную по тем или иным причинам прибыль. В некоторых случаях стоимость реинжиниринга программного обеспечения может превышать начальные инвестиции.

Можно выделить еще одну проблему, возникающую при модернизации действующего программного обеспечения, а именно то, что персонал не всегда готов к управленческим изменениям, Стимулирование же к обучению и переподготовке влекут за собой, как правило, дополнительные расходы, иногда несоразмерные с достигаемым результатом.

Нужно сказаться, что причины неудач модернизации системы информационного обеспечения как инвестиционного проекта, практически те же, как и для ординарного инвестиционного проекта (а, собственно, модернизация предприятия во всех ее аспектах и является разновидностью инвестиционного проекта), а именно:

- организация формирует некорректную или неполную стратегию реинжиниринга;

- наблюдается привлечение предприятием не всегда профессиональных внешних консультантов и подрядчиков;

- рабочая сила адаптирована к старым технологиям при отсутствии или недостаточности программ переобучения;

- организация не контролирует систему информационного обеспечения деятельности предприятия;

- обновление архитектуры программного обеспечения не является приоритетом реинжиниринга;

- существует система некорректного планирования, либо принимаемые решения не вытекают из плана и др.

Исходя из сказанного можно признать, что для реализации проекта модернизации программного обеспечения характерны те же ста- 
дии, как для типового инвестиционного проекта с учетом специфики, в частности: оценка текущего состояния системы информационного обеспечения; выбор подхода к модернизации; оценка возможных затрат и эффектов; создание графика вывода из эксплуатации действующей в настоящее время системы; формирование бюджета для повышения квалификации, переподготовки и адаптации персонала к новому программному обеспечению и другие.

\section{Библиографический список}

1. Агафонова М.С., Козярская Л.К. Совершенствование информационного обеспечения управления организацией // Научно-методический электронный журнал «Концепт». 2017. T. 39. С. 216-220. http://e-koncept. $\mathrm{ru} / 2017 / 970370 . \mathrm{htm}$.

2. Ермакова Ж.А. Технологическая модернизация промышленности России: стратегия и организационно-экономические факторы (региональный аспект): монография. Екатеринбург. 2007.

3. Ковальчук Ю.А. Модернизация как искусство управления современным предприятием: монография. Москва. 2010. 199 с.

4. МВФ понизил прогноз роста экономики России в 2019 и 2020 годах https://tass.ru/ekonomika/6022467. 21 января 2019 года.

5. Райзберг Б.А., Лозовский Л.Ш., Стародубцева Е. Б. Современный экономический словарь. Москва.1997. С.292.

6. Щепетов А.В. Модернизация и реконструкция предприятий: модели, методы, алгоритмы: монография. Москва. 2011.

7. Эйзенштадт Ш. Революция и преобразование обществ: Сравнительное изучение цивилизаций. Москва. 1999 